\title{
The Local Impact on the Concurrent Sentiment-Return Nexus: Asian versus European Markets
}

\author{
Ngoc Bao Vuong ${ }^{1,2 *}$, Yoshihisa Suzuki ${ }^{1}$, Anh Tho To ${ }^{3}$

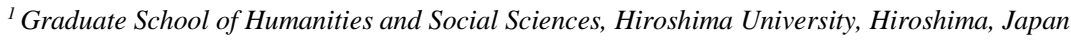 \\ ${ }^{2}$ Faculty of Finance, Banking and Business Administration, Quy Nhon University, Quy Nhon, Vietnam \\ ${ }^{3}$ University of Finance - Marketing, Ho Chi Minh, Vietnam
}

\begin{abstract}
We examine the relationship between investor sentiment and contemporaneous returns in sixteen Asian and European stock markets between 2004 and 2016. To identify the sentiment-return nexus, we use the OLS models with Newey-West standard errors as well as the panel regressions with cross-country fixed effects and time dummies. We report the regional outcomes for Asia, Europe, and the individual markets. Our empirical results reveal a significant effect of sentiment on stock returns, although those effects are nonidentical across markets. We find the dissimilarities in the sentiment-return relationship among the sample markets are driven negatively by almost all national factors, with the strongest determinants being the development of financial institutions and the quality of regulation. The impact of cultural dimensions among the sample markets, on the contrary, is relatively weak and mixed. Our research is the first to compare Asian and European outcomes and reveal which region is more vulnerable to the influence of the local components We detect that, except cultural aspects, European markets are more sensitive to country-specific characteristics than Asian ones.
\end{abstract}

\section{Keywords:}

Investor Sentiment;

Financial Development;

Governance Quality;

Cultural Characteristics;

Asia vs. Europe.

\section{Article History:}

Received: 27 July 2021

Revised: $\quad 03$ October 2021

Accepted: $\quad 14$ October 2021

Published: $01 \quad$ December 2021

\section{1- Introduction}

Recently, accompanying the introduction of behavioral finance, the sentiment-return inference has been investigated extensively. Although various studies have presented the remarkable impact of sentiment indicators on market returns [1-6], the results are considerably diverse between countries. That diversity is inspiring many researchers to determine the causes. For example, the stock characteristics proposed by Lee et al. (1991) [7], Berger and Turtle (2012) [8], and Ding et al. (2019) [9]. In addition, institutional governance and culture are also potential influencers of the sentimentreturn variations. In previous studies, the question about the role of those country-specific factors originates from the possible dependence of market performance on market development level. Porta et al. (1998) [10] find the link between legal and economic development while Chiou et al. (2010) [11] suggest that the legal affects risk premiums. Besides the legal environment, Turco et al. (2019) [12] emphasize that financial development eases the growth of industries highly dependent on external finance. In another view, country-specific cultural variations may lead to physiological biases, as stated by Chui et al. (2010) [13]. For example, Lee et al. (2019) [14] highlight that the average investor who lives in a state with relatively higher alcohol consumption is more likely to buy and sell lottery-type stocks and to trade more often. Following those ideas, several findings relating the contribution of country-specific characteristics to the sentiment divergences between countries have been reported.

\footnotetext{
*CONTACT: vbngoc139@gmail.com
}

DOI: http://dx.doi.org/10.28991/esj-2021-01318

(C) 2021 by the authors. Licensee ESJ, Italy. This is an open access article under the terms and conditions of the Creative Commons Attribution (CC-BY) license (https://creativecommons.org/licenses/by/4.0/). 
An analysis of eighteen developed countries proposes that countries with a tendency towards more overreaction-like and herd behavior, and countries that have less efficient regulatory institutions or less market integrity, are influenced stronger by sentiment than others [15]. By expanding the sample scope to twenty-three countries, including both developed and developing countries, Chang et al. (2012) [16] provide evidence that a strong legal environment is generally negatively associated with sentiment effects. Their findings suggest that improvements in the legal settings mitigate the impact of sentiment on the stock market by facilitating arbitrage. They also demonstrate that stricter rules of law and higher accounting standards enhance the global sentiment impact, in contrast to improvements in the legal settings. In addition, the global sentiment enhancement increases with the accessibility of a country's stock market. In a similar vein, stock features as well as cross-country institutional or cultural norms play a role in the sentiment diversity between Germany, France, United Kingdom, and Spain as demonstrated by Corredor et al. (2013) [17]. More recently, the research of Lee et al. (2020) [18] indicates that a higher United States of America (U.S.) and a home countries' freedom to make life choices, absence of corruption perception, and confidence in national government precede higher exchange-traded fund returns. Furthermore, the effect of business sentiment is stronger in hard-to-value markets and in markets based in countries with collectivistic national cultures, as stated by Zaremba et al. (2020) [19] from their analyses of thirty-seven developed and developing countries. On the other hand, local characteristics of the Czech Republic, Hungary, and Poland, at least separately, do not influence the sentiment impact on their market returns, according to Corredor et al. (2015) [20].

Collectively, although a potential effect of local factors on the sentiment-return relationship was outlined throughout prior research, a conclusion on the role of country-specific factors has not been robustly proved. The lack of a robust conclusion could be due to insufficient studies and controversial results if compared to studies of stock characteristics. Moreover, works on the effect of country-specific factors have some limitations. For example, the focus on developed countries that have an equivalent growth level can limit, or rule out, the role of market development [15, 17]. Additionally, the choice of Central European countries with similar characteristics as a sample causes difficulties and limitations in the detection of the "country-only" influences [20]. Likewise, limitations can come from examining only one part of governance or cultural dimensions $[15,16,18,19]$. Limitations are especially clear, as the possible differences in the local effect across regions have not been questioned. As a result of the previous limitations, we use a variety of Asian and European countries with different national characteristics, as well as the inclusion of the indicators for market development. We hope to fill those gaps and reveal a more comprehensive picture of the sentiment-return relationship.

In general, our paper makes the following contributions to financial literacy. First, we provide more empirical evidence about the contemporary connection between investor sentiment and stock returns for many Asian and European markets. Second, by expanding to fourteen country-specific factors, we investigate and detect the role of local characteristics in driving the sentiment-return nexus. Third, we compare the results between Asia and Europe to reveal which region is more vulnerable to the effect of these components. That type of comparison has never been done before. Our findings bring useful information in selecting suitable markets to investors who want to earn profit from price changes due to herding behavior towards stock and who seek diversification benefits through foreign investments.

\section{2- Data and Methodology}

\section{2-1-Data}

Our sample includes monthly data from sixteen countries in which nine are developed (Japan, South Korea, Belgium, France, Italy, the Netherlands, Sweden, Switzerland, and the United Kingdom) and seven are developing (China, Indonesia, the Philippines, Pakistan, the Czech Republic, Greece, and Russia) during the period from January 2004 to December 2016. In terms of geographical location, our sample comprises six Asian and ten European markets. Our sample covers half of the total countries of those two areas, and we use realistic proportions between the Asian and European or the developed and developing countries. The countries are selected from different parts of each region to ensure the diversity of local characteristics. All data are acquired from the Thomson Reuters Datastream, except the indices of national factors. We implement a cubic spline interpolation to generate monthly data from time series that are only available quarterly*.

\section{2-1-1- Stock Returns and Market Sentiment Proxy}

In the first place, we obtain a market's end-of-month price index in local currency, then we apply the following formula to create monthly stock returns for each market: $R_{i, t}=100 * \ln \left(P I_{i, t} / P I_{i, t-1}\right)$. By collecting the price indices in local currency, we aim to reduce the exchange rate and currency risks. Besides market returns, another vital issue is how to measure sentiment. Looking back on earlier works, scientists have used a variety of proxies to measure sentiment. From using explicit indicators such as public surveys [1, 15, 20, 21], option implied volatility [22-24], investor mood [6, 25],

\footnotetext{
* This method is also used in the research of Bathia and Bredin (2013) [2]
} 
text-based index [5, 26]; and implicit indicators, including mutual fund flows [27, 28], closed-end fund discount [29, 30], turnover or trading volume [31-34], number of IPOs and first-day returns on IPOs [35], share of equity issues in total debt and equity issues [36]. To using composite sentiment indexes that combine some of these proxies [3, 4, 17, 37]. Nonetheless, there is no clear evidence that one method of measurement is more effective than another. To find a consistent sentiment proxy, we use market turnover because it is not only employed widely in prior research [31-34] but also is one of a few proxies that are available for all markets. Imitating Baker et al. (2012) [38], we have:

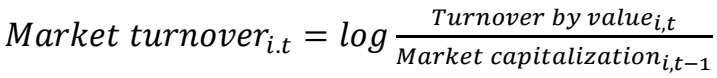

We expect the synchronous calculation in stock returns and investor sentiment can make our results more comparable across markets. The descriptive statistics for these two variables are presented in Table 1. Regarding the Asian region, what stands out in Table 1 is the positive average returns of all markets, with the lowest being Japan at $0.254 \%$ and the highest being Indonesia at $1.240 \%$ per month. By earning higher average returns, emerging markets, excluding China, seem to outperform developed ones during our research period. Although China has a moderate monthly return of $0.459 \%$, it is the riskiest market with a standard deviation of 8.486, followed by Pakistan and Indonesia with 7.283 and 6.293, respectively. On the other hand, investors interested in the Asian region should consider the Philippines as a potential market since this country witnesses the second-highest stock returns of $0.954 \%$ and the lowest standard deviation of 4.883. Lastly, all Asian return series are left-tailed and four out of six are leptokurtic.

Table 1. Summary statistics for main variables.

\begin{tabular}{|c|c|c|c|c|c|c|c|}
\hline & & Mean & Min. & Max. & SD & Skewness & Ex. Kurtosis \\
\hline \multicolumn{8}{|c|}{ Panel A. Asia } \\
\hline \multirow{2}{*}{ China } & Stock Returns & 0.459 & -31.155 & 19.012 & 8.486 & -0.583 & -1.858 \\
\hline & Market Turnover & -1.027 & -1.321 & -0.562 & 0.170 & 0.539 & -3.612 \\
\hline \multirow{2}{*}{ Indonesia } & Stock Returns & 1.240 & -38.843 & 17.608 & 6.293 & -1.822 & 7.148 \\
\hline & Market Turnover & -1.618 & -1.944 & -1.149 & 0.184 & 0.407 & -3.669 \\
\hline \multirow{2}{*}{ Japan } & Stock Returns & 0.254 & -22.233 & 11.840 & 5.218 & -0.682 & -1.335 \\
\hline & Market Turnover & -1.030 & -1.229 & -0.722 & 0.087 & 0.111 & -1.928 \\
\hline \multirow{2}{*}{ South Korea } & Stock Returns & 0.561 & -24.455 & 12.525 & 5.265 & -0.751 & 0.019 \\
\hline & Market Turnover & -1.043 & -1.335 & -0.655 & 0.163 & 0.065 & -3.925 \\
\hline \multirow{2}{*}{ Philippines } & Stock Returns & 0.954 & -24.229 & 13.844 & 4.883 & -0.882 & 1.055 \\
\hline & Market Turnover & -1.857 & -2.177 & -1.594 & 0.118 & -0.122 & -3.295 \\
\hline \multirow{2}{*}{ Pakistan } & Stock Returns & 0.928 & -48.665 & 20.612 & 7.283 & -2.266 & 10.736 \\
\hline & Market Turnover & -1.300 & -5.303 & -0.082 & 0.662 & -1.987 & 8.198 \\
\hline \multicolumn{8}{|c|}{ Panel B. Europe } \\
\hline \multirow{2}{*}{ Belgium } & Stock Returns & 0.528 & -29.572 & 11.752 & 4.988 & -2.021 & 6.196 \\
\hline & Market Turnover & -1.450 & -1.701 & -1.120 & 0.122 & 0.575 & -3.128 \\
\hline \multirow{2}{*}{ Czech Republic } & Stock Returns & 0.411 & -23.254 & 14.160 & 5.401 & -0.582 & -0.828 \\
\hline & Market Turnover & -1.485 & -1.910 & -0.829 & 0.265 & 0.485 & -3.769 \\
\hline \multirow{2}{*}{ France } & Stock Returns & 0.332 & -14.458 & 12.730 & 4.529 & -0.688 & -2.033 \\
\hline & Market Turnover & -1.189 & -1.457 & -0.868 & 0.115 & 0.076 & -3.526 \\
\hline \multirow{2}{*}{ Greece } & Stock Returns & -1.342 & -34.871 & 18.494 & 9.662 & -0.831 & -1.997 \\
\hline & Market Turnover & -1.382 & -1.830 & -0.871 & 0.144 & -0.243 & -2.043 \\
\hline \multirow{2}{*}{ Italy } & Stock Returns & -0.050 & -16.693 & 16.352 & 5.426 & -0.454 & -2.429 \\
\hline & Market Turnover & -0.915 & -1.183 & -0.634 & 0.096 & 0.117 & -2.754 \\
\hline \multirow{2}{*}{ Netherlands } & Stock Returns & 0.295 & -27.362 & 11.560 & 5.277 & -1.759 & 3.642 \\
\hline & Market Turnover & -1.070 & -1.315 & -0.771 & 0.119 & 0.165 & -3.325 \\
\hline \multirow{2}{*}{ Russia } & Stock Returns & 0.841 & -34.869 & 18.714 & 7.370 & -1.082 & 0.720 \\
\hline & Market Turnover & -1.462 & -1.925 & -1.053 & 0.161 & 0.361 & -2.797 \\
\hline \multirow{2}{*}{ Sweden } & Stock Returns & 0.653 & -19.672 & 17.295 & 4.880 & -0.859 & 0.145 \\
\hline & Market Turnover & -1.076 & -1.382 & -0.779 & 0.164 & 0.044 & -4.187 \\
\hline \multirow{2}{*}{ Switzerland } & Stock Returns & 0.335 & -11.622 & 8.813 & 3.553 & -0.695 & -2.155 \\
\hline & Market Turnover & -1.228 & -1.521 & -0.863 & 0.132 & 0.419 & -2.985 \\
\hline \multirow{2}{*}{ United Kingdom } & Stock Returns & 0.350 & -14.887 & 10.023 & 3.848 & -0.799 & -1.139 \\
\hline & Market Turnover & -1.154 & -1.502 & -0.768 & 0.206 & 0.291 & -4.395 \\
\hline
\end{tabular}


Unlike Asia, there are no significant differences between developed and emerging European markets in Table 1. Specifically, the monthly average returns range from $0.295 \%$ in the Netherlands to $0.841 \%$ in Russia. Greece and Italy's stock markets are the only ones that, in turn, experience negative average returns of $-1.342 \%$ and $-0.050 \%$ per month. Their outcomes are predictable as these two countries are one of the slowest gainers since the Great Recession. Greek stocks also have the highest standard deviation of 9.662, while other countries fluctuate between 3 and 5 , excluding Russia that has a standard deviation of 7.370. One more dissimilarity between the Asian and European markets is that all European return series are also left-tailed but mainly platykurtic.

In contrast to the stock returns, the statistics of market turnover are almost indistinguishable among the sixteen countries. The indistinguishability is because the averages are negative and vary from -1.857 for the Philippines to 0.915 for Italy. Additionally, their standard deviations are relatively small with the largest belonging to Pakistan at 0.662 . Lastly, the turnover series are mostly right-tailed (thirteen out of sixteen series) and leptokurtic (fifteen out of sixteen series).

\section{2-1-2- Macroeconomic Variables}

Other studies report that business conditions can affect market outcomes [39, 40]. Consequently, to remove the impact of economic cycles and to make sure the return fluctuations in our study are driven by sentiment purely, we include three macroeconomic variables into our regression models. These are the industrial production index, unemployment rate, and consumer price index, following Gao et al. (2020) [5], Anusakumar et al. (2017) [34], and Finter et al. (2012) [37]. Before we use those macroeconomic variables, all the monthly series are transformed to growth rates.

\section{2-1-3- Local factors}

We investigate the role of country-specific characteristics in the sentiment-return variations by applying three sets of national data, include the Financial Development Index (FDI), the Worldwide Governance Indicators (WGI), and Hofstede's cultural dimensions.

The FDI measures how developed financial institutions and financial markets are in terms of their depth (size and liquidity), access (the ability of individuals and companies to access financial services), and efficiency (the ability of institutions to provide financial services at low cost and with sustainable revenue and the level of activity of capital markets). The FDI series, including the Financial Institutions (FI) and the Financial Markets $(F M)$, are obtained from the International Monetary Fund (IMF)'s website.

On the other hand, the WGI presents total and individual scores for six governance dimensions: Voice and Accountability (VA), Political Stability and Absence of Violence ( $P A)$, Government Effectiveness $(G E)$, Regulatory Quality $(R Q)$, Rule of Law $(R L)$, and Control of Corruption $(C C)$. Specifically, $V A$ measures the degree of freedom of a country's citizens, $P A$ captures the level of political instability, $G E$ reflects the quality of public services and their independence from politics, $R Q$ explores the quality in policies and regulations of government toward the private sector, $R L$ demonstrates the extent to which rules of society are implemented, and $C C$ expresses how the public power is executed for private benefits. These data series are based on over 30 underlying data sources and are accessible via the World Bank's database.

Finally, the national culture data series that are modelled by Professors Geert Hofstede, Gert Jan Hofstede, Michael Minkov, and their research teams are downloadable from the Hofstede Insights' website. They consist of six aspects of culture: the Power Distance Index (PDI) series that expresses the degree to which the less severe members of a society accept and expect that power is distributed unequally, the Individualism vs. Collectivism (IDV) series that explores the degree to which people in a society are integrated into groups, the Uncertainty Avoidance Index (UAI) series that expresses the degree to which the members of a society feel uncomfortable with uncertainty and ambiguity, the Masculinity vs. Femininity $(M A S)$ series that captures the degree of competitiveness in a society, the Long-term Orientation vs. Short-term Orientation (LTO) series that associates the connection of the past with current and future actions/challenges, and the Indulgence vs. Restraint (IVR) series that refers to the degree of freedom that societal norms give to citizens in fulfilling their human desires.

The average yearly scores from the fourteen local factors of the FDI, the WGI, and Hofstede's cultural dimensions are presented in Tables 2 and 3 by country between 2004 and 2016. Tables 2 and 3 also contain information about regional scores computed from the averages of all regional countries.

As can be seen from Table 2, Switzerland is the most developed country in terms of financial and governance quality, with its scores being in the top two of seven factors, followed closely by Sweden and the Netherlands. Those three countries are all in Europe. In contrast, Pakistan has the lowest total score among all sample countries by ranking at the bottom of five out of eight factors. Overall, the growth level of Asia, particularly in institutional regulations, seems to lag behind Europe with remarkable distances which can be observed in Figure 1. 
Table 2. National and regional scores on financial development and institutional factors.

\begin{tabular}{|c|c|c|c|c|c|c|c|c|}
\hline & FI & FM & $\mathrm{CC}$ & GE & PA & RQ & RL & VA \\
\hline \multicolumn{9}{|c|}{ Panel A. Asia } \\
\hline China & 0.493 & 0.584 & -0.465 & 0.124 & -0.522 & -0.233 & -0.479 & -1.635 \\
\hline Indonesia & 0.344 & 0.305 & -0.679 & -0.251 & -0.922 & -0.343 & -0.592 & 0.005 \\
\hline Japan & 0.888 & 0.761 & 1.455 & 1.543 & 0.996 & 1.167 & 1.369 & 1.021 \\
\hline South Korea & 0.804 & 0.840 & 0.500 & 1.104 & 0.342 & 0.923 & 0.980 & 0.699 \\
\hline Philippines & 0.337 & 0.362 & -0.622 & 0.020 & -1.377 & -0.125 & -0.455 & 0.003 \\
\hline Pakistan & 0.295 & 0.254 & -0.956 & -0.655 & -2.396 & -0.641 & -0.848 & -0.851 \\
\hline Asia & 0.527 & 0.518 & -0.128 & 0.314 & -0.647 & 0.125 & -0.00 & -0.126 \\
\hline \multicolumn{9}{|c|}{ Panel B. Europe } \\
\hline Belgium & 0.681 & 0.492 & 1.495 & 1.576 & 0.763 & 1.302 & 1.381 & 1.367 \\
\hline Czech Republic & 0.522 & 0.234 & 0.372 & 0.958 & 0.984 & 1.117 & 0.978 & 0.998 \\
\hline France & 0.886 & 0.643 & 1.406 & 1.498 & 0.428 & 1.195 & 1.455 & 1.264 \\
\hline Greece & 0.635 & 0.553 & 0.075 & 0.511 & 0.085 & 0.651 & 0.600 & 0.854 \\
\hline Italy & 0.806 & 0.753 & 0.198 & 0.425 & 0.448 & 0.860 & 0.425 & 1.022 \\
\hline Netherlands & 0.798 & 0.744 & 2.051 & 1.814 & 0.982 & 1.769 & 1.833 & 1.552 \\
\hline Russia & 0.468 & 0.464 & -0.977 & -0.367 & -0.975 & -0.338 & -0.835 & -0.913 \\
\hline Sweden & 0.772 & 0.711 & 2.213 & 1.929 & 1.161 & 1.720 & 1.942 & 1.587 \\
\hline Switzerland & 0.968 & 0.846 & 2.087 & 1.978 & 1.299 & 1.650 & 1.850 & 1.574 \\
\hline United Kingdom & 0.902 & 0.805 & 1.753 & 1.636 & 0.390 & 1.743 & 1.723 & 1.346 \\
\hline Europe & 0.744 & 0.625 & 1.067 & 1.196 & $\mathbf{0 . 5 5 7}$ & 1.167 & 1.135 & 1.065 \\
\hline
\end{tabular}

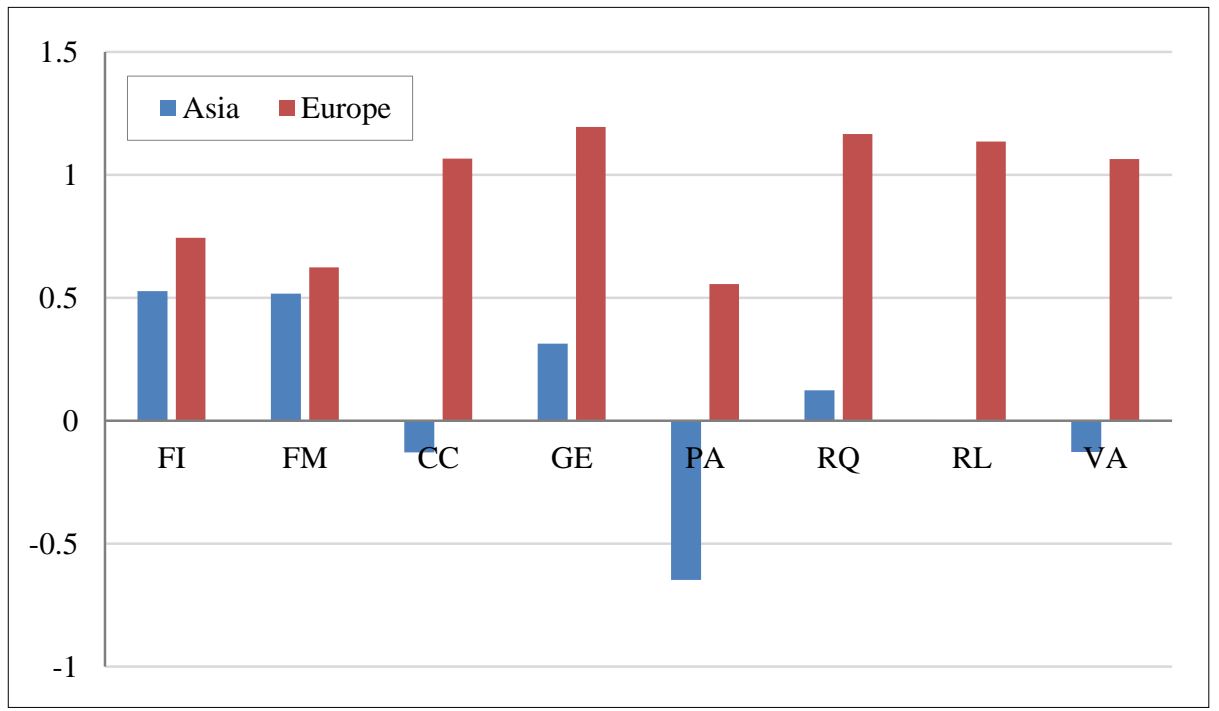

Figure 1. Financial development and governance quality: Asia vs. Europe.

As for cultural characteristics, Table 3 and Figure 2 show some interesting insights. To begin, Greece and South Korea have full scores on $U A I$ and $L T O$, respectively. These scores indicate that among others, Greeks are the most uncomfortable by unknown situations, whereas South Koreans tend to emphasize the long-term effects when making present decisions. In contrast, at 0 on $I V R$, Pakistan might be described as a very restrained society where people need to control their desires under the pressure of social norms. Among the sixteen countries, Sweden gets the lowest score on three cultural aspects $P D I, M A S$, and $U A I$, and the highest score on $I V R$, which causes it to become one of the top nations in terms of life quality. On average, all the Asian countries are collectivistic and restrained societies, while most of the European countries are individualistic and indulgent. Asian people, on average, are also more likely to accept a hierarchical order (high PDI scores) where everybody has their place and juniors are expected to obey seniors' commands, which partly leads to more competitive societies (high MAS scores). On the other hand, there are no significant differences between Asian and European countries in the matter of uncertainty avoidance and long-term orientations based on the average scores of regional $U A I$ and $L T O$. 
Table 3. National and regional scores on cultural dimensions.

\begin{tabular}{|c|c|c|c|c|c|c|}
\hline & PDI & IDV & MAS & UAI & LTO & IVR \\
\hline \multicolumn{7}{|c|}{ Panel A. Asia } \\
\hline China & 80 & 20 & 66 & 30 & 87 & 24 \\
\hline Indonesia & 78 & 14 & 46 & 48 & 62 & 38 \\
\hline Japan & 54 & 46 & 95 & 92 & 88 & 42 \\
\hline South Korea & 60 & 18 & 39 & 85 & 100 & 29 \\
\hline Philippines & 94 & 32 & 64 & 44 & 27 & 42 \\
\hline Pakistan & 55 & 14 & 50 & 70 & 50 & 0 \\
\hline Asia & 70.2 & 24 & 60 & 61.5 & 69 & 29.2 \\
\hline \multicolumn{7}{|c|}{ Panel B. Europe } \\
\hline Belgium & 65 & 75 & 54 & 94 & 82 & 57 \\
\hline Czech Republic & 57 & 58 & 57 & 74 & 70 & 29 \\
\hline France & 68 & 71 & 43 & 86 & 63 & 48 \\
\hline Greece & 60 & 35 & 57 & 100 & 45 & 50 \\
\hline Italy & 50 & 76 & 70 & 75 & 61 & 30 \\
\hline Netherlands & 38 & 80 & 14 & 53 & 67 & 68 \\
\hline Russia & 93 & 39 & 36 & 95 & 81 & 20 \\
\hline Sweden & 31 & 71 & 5 & 29 & 53 & 78 \\
\hline Switzerland & 34 & 68 & 70 & 58 & 74 & 66 \\
\hline United Kingdom & 35 & 89 & 66 & 35 & 51 & 69 \\
\hline Europe & 53.1 & 66.2 & 47.2 & 69.9 & 64.7 & 51.5 \\
\hline
\end{tabular}

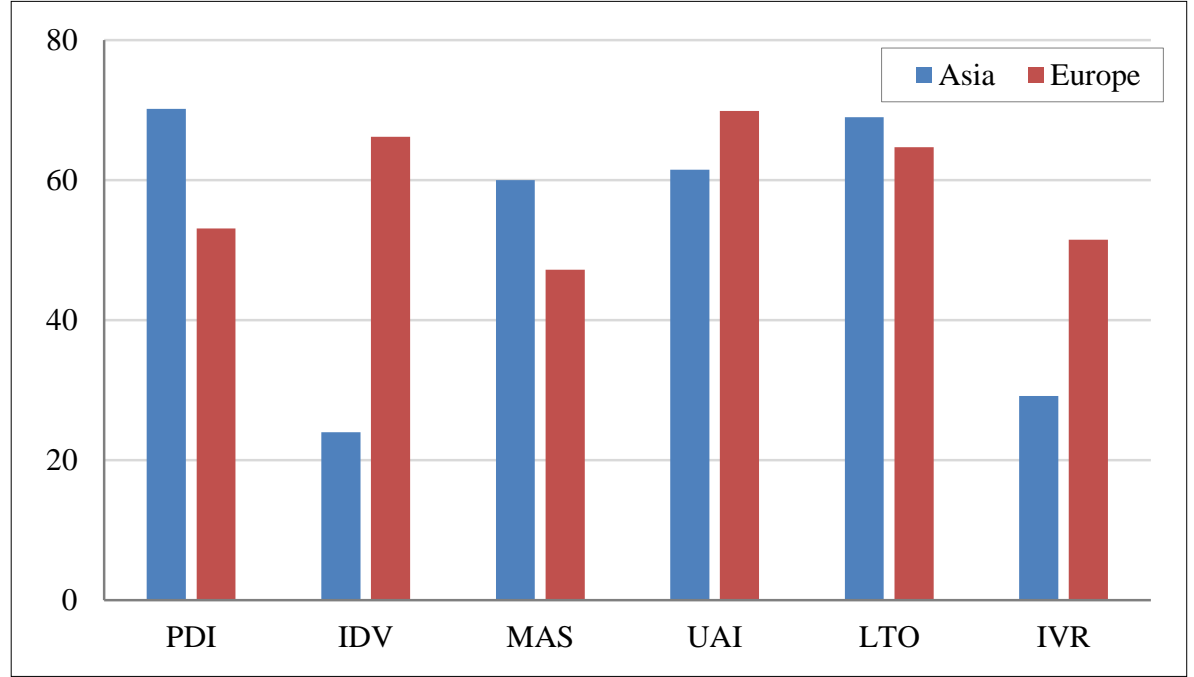

Figure 2. Cultural dimensions: Asia vs. Europe.

\section{2-2-Methodology}

Before executing empirical analysis, we employ the Augmented Dickey-Fuller (ADF) and the Kwiatkowski-PhillipsSchmidt-Shin (KPSS) tests to check whether all data series are stationary. If the series is proven to have a unit root, its first differencing is used instead.

First, to test the impact of market sentiment on contemporaneous returns, the following OLS model with NeweyWest standard errors is run for each country. The regional results for Asia and Europe are reported after manipulating the fixed-effect panel regressions with time dummies and cross-section clustered standard errors.

$R_{i, t}=\alpha_{i}+\beta_{i} \operatorname{Sent}_{i, t}+\gamma_{i} \psi_{i, t}+\varepsilon_{i, t}$

where; $R_{i . t}$ is the market returns of country $i$ at month $t$, Sent $t_{i, t}$ is the market sentiment of country $i$ at month $t, \psi_{i, t}$ is the matrix of macroeconomic variables of country $i$ at month $t$, including the industrial production index, the unemployment rate, and the consumer price index. 
Additionally, we add an interaction term between sentiment and country-specific factors into Equation 2 and execute the model for all countries together to check whether each national element affects the sentiment-returns relationship.

$R_{i, t}=\alpha_{i}+\beta_{i}$ Sent $_{i, t}+\gamma_{i}$ Sent $_{i, t} *$ Index $_{i}+\delta_{i} \psi_{i, t}+\varepsilon_{i, t}$

Finally, to differentiate the local impact between Asian and European areas, a dummy variable, namely EU, which receives a value of 1 for European countries and 0 for otherwise, is created. Then the model combining sentiment, country-level factors, and this dummy variable is utilized.

$R_{i, t}=\alpha_{i}+\beta_{i}$ Sent $_{i, t}+\gamma_{i}$ Sent $_{i, t} *$ Index $_{i}+\delta_{i}$ Sent $_{i, t} *$ Index $_{i} * E U+\theta_{i} \psi_{i, t}+\varepsilon_{i, t}$

The main steps of our research analyses are summarized in Figure 3.

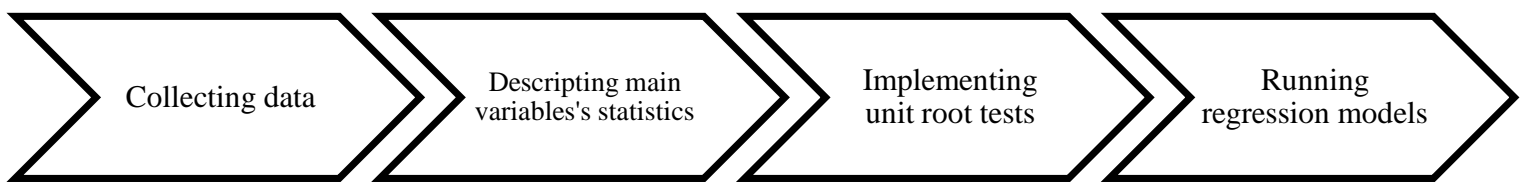

Figure 3. Flowchart of the research methodology.

\section{3- Results}

\section{3-1-Investor Sentiment and Market Returns}

Table 4 shows the concurrent impact of sentiment on stock returns in Asian and European markets by solving Equation 2. A positive relationship between sentiment and returns is witnessed in all Asian markets. Notably, the coefficients are relatively similar in most markets with the magnitude fluctuating between $1.017(\mathrm{p}$-value $=0.001)$ for the Philippines and 1.514 (p-value $=0.012$ ) for Pakistan if we exclude Japan that has a much smaller coefficient of 0.336 (p-value $=0.532)$. These results imply that the Japanese stock market is the least affected by sentiment, whereas the Indonesian and Pakistanis markets are highly vulnerable to the sentiment effect.

In contrast, the European markets' outcomes are not homogeneous. Sentiment influences negatively on stock returns in seven out of ten markets, with Greece, Italy, and Russia being the exceptions. Our work supports the results of Chen et al. (2001) [31] that report a positive correlation between trading volume and the absolute value of the stock price change in Italy. However, their findings for France and the Netherlands are opposite to ours, because they detect that trading volume positively affects stock returns on these markets. Apart from that, Brüggemann et al. (2014) [33] investigate sixteen European countries, eight of them are the same as our sample, and find no evidence for the influence of trading volume on returns.

Table 4. Sentiment impact on concurrent market returns.

\begin{tabular}{|c|c|c|c|c|}
\hline & Coef. & p-value & Adj. $R^{2}$ & F-stat. \\
\hline \multicolumn{5}{|c|}{ Panel A. Asia } \\
\hline China & 1.089 & 0.113 & $2.28 \%$ & 2.609 \\
\hline Indonesia & 1.257 & $0.047 * *$ & $1.92 \%$ & 1.282 \\
\hline Japan & 0.336 & 0.532 & $2.45 \%$ & 3.928 \\
\hline South Korea & 1.149 & $0.016^{* *}$ & $5.47 \%$ & 2.734 \\
\hline Philippines & 1.017 & $0.001 * * *$ & $4.69 \%$ & 4.086 \\
\hline Pakistan & 1.514 & $0.012 * *$ & $2.32 \%$ & 2.499 \\
\hline Asia & 1.062 & $0.000 * * *$ & $49.52 \%$ & 5.850 \\
\hline \multicolumn{5}{|c|}{ Panel B. Europe } \\
\hline Belgium & -1.037 & $0.013 * *$ & $3.23 \%$ & 2.706 \\
\hline Czech Republic & -1.454 & $0.024 * *$ & $6.69 \%$ & 2.483 \\
\hline France & -1.314 & $0.000 * * *$ & $8.76 \%$ & 3.891 \\
\hline Greece & 2.398 & $0.030 * *$ & $3.72 \%$ & 1.257 \\
\hline Italy & 0.118 & 0.774 & $0.12 \%$ & 1.151 \\
\hline Netherlands & -1.367 & $0.007 * * *$ & $6.07 \%$ & 3.088 \\
\hline Russia & 1.365 & $0.005^{* * *} *$ & $1.42 \%$ & 2.987 \\
\hline Sweden & -0.669 & $0.075^{*}$ & $2.54 \%$ & 1.620 \\
\hline Switzerland & -1.313 & $\sim 0 * * *$ & $18.80 \%$ & 10.084 \\
\hline United Kingdom & -0.980 & $0.009 * * *$ & $7.80 \%$ & 2.476 \\
\hline Europe & 0.796 & $0.002 * * *$ & $58.54 \%$ & 16.410 \\
\hline
\end{tabular}

$*, * *, * * *$ indicate $0.1,0.05$, and 0.01 significance level, respectively. 

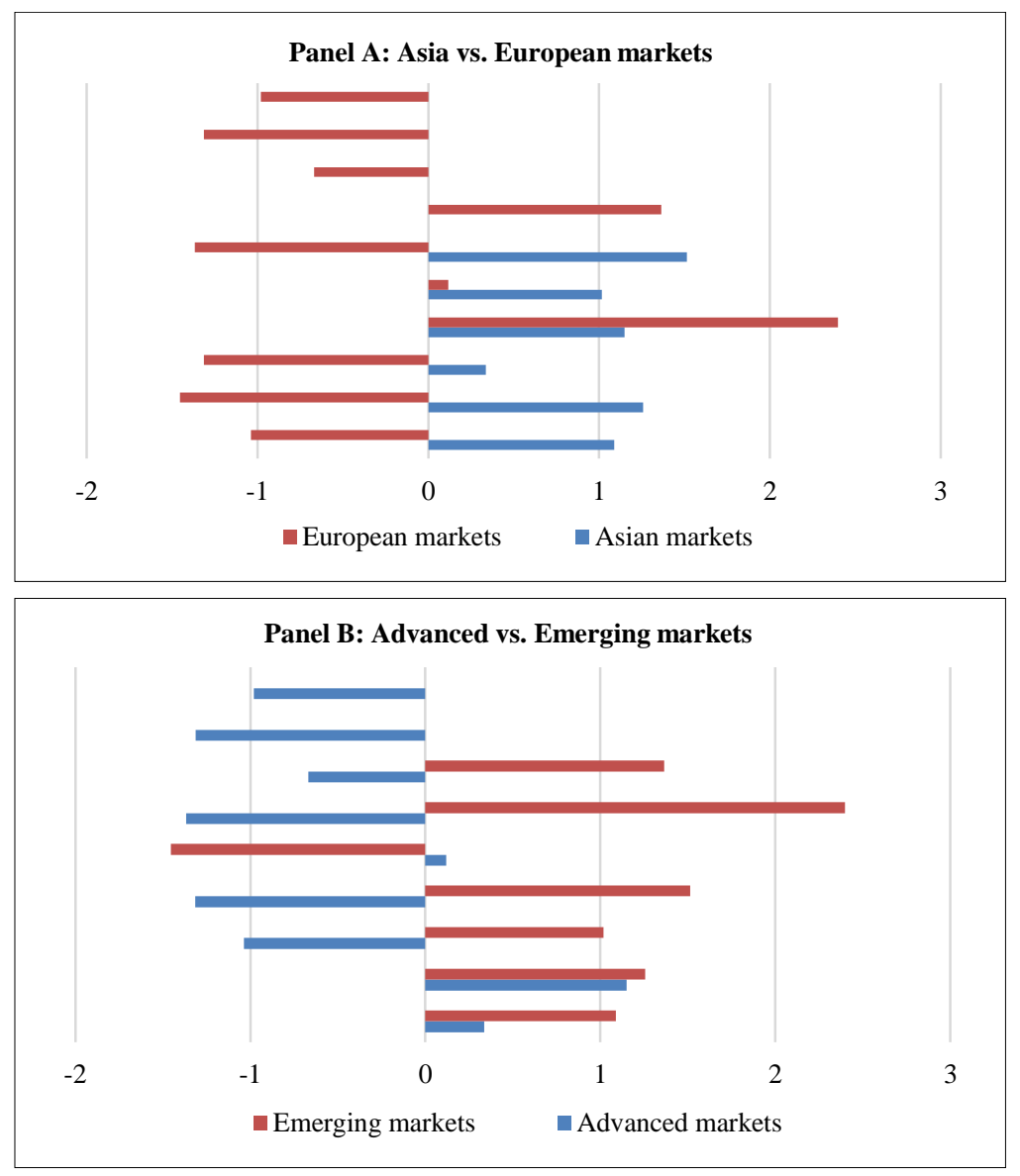

Figure 4. Sentiment impact on market returns.

Furthermore, we notice that the variances in sentiment intensity are greater in Europe than in Asia. The greater variance in Europe is indicated by the lowest coefficient belongs to the Czech Republic at -1.454 ( $p$-value $=0.024)$, and the highest is 2.398 for Greece (p-value $=0.030$ ). The European results, together with the preceding analyses for the Asian region, prove the idea that emerging markets are likely more susceptible to sentiment than developed ones, which was questioned in the paper of Corredor et al. (2015) [20].

Turning now to a broader perspective, the regional results from the panel regressions claim the same pattern for Asia and Europe with positive estimated coefficients of the market sentiment of 1.062 (p-value $=0.000)$ and 0.796 ( $p$-value $=0.002$ ), respectively. Our regional observations are in tandem with Anusakumar et al. (2017) [34], who examine the connection between investor sentiment and stock returns in eight Asian emerging markets. Overall, investor sentiment economically and statistically influences contemporaneous returns. Even so, the variations in sentiment impact between markets, particularly in Europe, raise concerns regarding the potential role of country-specific factors on moderating the sentiment-return relationship, as discussed in the next section.

\section{3-2-Effect of Country-specific Factors}

To begin, we discuss the results for Model 1, as presented in the first two columns of Table 5. The negative coefficients of interaction variables between sentiment and local features indicate that all the financial development and the governance factors moderate the sentiment-return relationship negatively, although only five out of eight coefficients are statistically significant. In other words, for advanced markets with superior institutional qualities, the sentiment effect is weakened and vice versa. Our findings support the hypothesis that emerging markets are more vulnerable to the sentiment effect than advanced markets, as demonstrated in the preceding section.

Among the development and governance components, the maturing of financial institutions has the greatest effect, with its coefficients being -1.104 ( $\mathrm{p}$-value $=0.087$ ). At the same time, the effects of governance factors are almost equivalent, with the lowest and highest coefficients of -0.290 (p-value $=0.135$ ) for $P A$ and $-0.463(\mathrm{p}$-value $=0.012)$ for $R Q$. Our results for institutional characteristics are consistent with the global results of Schmeling (2009) [15], Chang et al. (2012) [16], and Lee et al. (2020) [18]. As stated by Chang et al. (2012) [16], two conditions are necessary to support the existence of sentiment effects in financial markets. First, that enough numbers of investors are subject to the sentiment, a.k.a. "behavioral investors." Second, that certain traded assets are difficult to value and/or difficult to arbitrage. Consequently, the sentiment effect in each market is expected to depend on the relative importance of behavioral investors versus arbitrageurs for that setting. Indeed, the more the former investor type dominates the latter, 
the more we expect to see the sentiment effect. Therefore, the negatively moderating effect of the development and governance factors on the sentiment-return relationship observed in our study is reasonable because the role of "behavioral investors" is assumed to lessen in developed markets.

Table 5. Effect of country-specific factors on the sentiment-return relationship.

\begin{tabular}{|c|c|c|c|c|c|}
\hline & & \multicolumn{2}{|c|}{ Model 1} & \multicolumn{2}{|c|}{ Model 2} \\
\hline & & Coef. & p-value & Coef. & p-value \\
\hline \multicolumn{6}{|c|}{ Panel A. Financial Development Indices } \\
\hline \multirow{3}{*}{ Financial Institutions $(F I)$} & Sent & 1.490 & $0.004 * * *$ & 1.216 & $0.021^{* *}$ \\
\hline & Sent*Index & -1.104 & $0.087 *$ & -0.050 & 0.945 \\
\hline & Sent*Index*EU & & & -0.977 & $0.006 * * *$ \\
\hline \multirow{3}{*}{ Financial Markets $(F M)$} & Sent & 0.989 & $0.026^{* *}$ & 0.782 & $0.077 *$ \\
\hline & Sent*Index & -0.342 & 0.563 & 0.697 & 0.285 \\
\hline & Sent*Index*EU & & & -1.144 & $0.005^{* * *}$ \\
\hline \multicolumn{6}{|c|}{ Panel B. Institutional Factors } \\
\hline \multirow{3}{*}{ Control of Corruption $(C C)$} & Sent & 0.937 & $0.000 * * *$ & 0.997 & $0.000 * * *$ \\
\hline & Sent*Index & -0.318 & $0.006 * * *$ & -0.052 & 0.850 \\
\hline & Sent*Index*EU & & & -0.355 & 0.199 \\
\hline \multirow{3}{*}{ Government Effectiveness $(G E)$} & Sent & 1.071 & $0.000 * * *$ & 1.088 & $0.000 * * *$ \\
\hline & Sent*Index & -0.382 & $0.030 * *$ & 0.132 & 0.688 \\
\hline & Sent*Index*EU & & & -0.651 & $0.012 * *$ \\
\hline \multirow{3}{*}{ Political Stability and Absence of Violence $(P A)$} & Sent & 0.777 & $0.000 * * *$ & 0.991 & $0.000 * * *$ \\
\hline & Sent*Index & -0.290 & 0.135 & 0.007 & 0.982 \\
\hline & Sent*Index*EU & & & -0.781 & $0.035^{* *}$ \\
\hline \multirow{3}{*}{ Regulatory Quality $(R Q)$} & Sent & 1.090 & $0.000 * * *$ & 1.148 & $0.000 * * *$ \\
\hline & Sent*Index & -0.463 & $0.012 * *$ & 0.002 & 0.996 \\
\hline & Sent*Index*EU & & & -0.599 & $0.030 * *$ \\
\hline \multirow{3}{*}{ Rule of Law $(R L)$} & Sent & 0.987 & $0.000 * * *$ & 1.075 & $0.000 * * *$ \\
\hline & Sent*Index & -0.360 & $0.014 * *$ & 0.006 & 0.982 \\
\hline & Sent*Index*EU & & & -0.516 & $0.051 *$ \\
\hline \multirow{3}{*}{ Voice and Accountability (VA) } & Sent & 0.962 & $0.000 * * *$ & 0.972 & $0.000 * * *$ \\
\hline & Sent*Index & -0.364 & 0.154 & 0.202 & 0.442 \\
\hline & Sent*Index*EU & & & -0.694 & $0.007 * * *$ \\
\hline \multicolumn{6}{|c|}{ Panel C. Cultural Dimensions } \\
\hline \multirow{3}{*}{ Power Distance Index $(P D I)$} & Sent & -0.535 & 0.111 & -0.353 & 0.353 \\
\hline & Sent*Index & 0.022 & $0.000 * * *$ & 0.022 & $0.000 * * *$ \\
\hline & Sent*Index*EU & & & -0.007 & 0.157 \\
\hline \multirow{3}{*}{ Individualism vs. Collectivism (IDV) } & Sent & 1.638 & $0.000 * * *$ & 1.495 & $0.005^{* * *}$ \\
\hline & Sent*Index & -0.018 & $0.001 * * *$ & -0.011 & 0.499 \\
\hline & Sent*Index*EU & & & -0.006 & 0.555 \\
\hline \multirow{3}{*}{ Masculinity vs. Femininity $(M A S)$} & Sent & 0.434 & $0.087^{*}$ & 0.490 & $0.058^{*}$ \\
\hline & Sent*Index & 0.007 & $0.063^{*}$ & 0.011 & $0.011^{* *}$ \\
\hline & Sent*Index*EU & & & -0.010 & $0.033^{* *}$ \\
\hline \multirow{3}{*}{ Uncertainty Avoidance Index (UAI) } & Sent & 0.633 & $0.043 * *$ & 0.501 & 0.095 \\
\hline & Sent*Index & 0.002 & 0.618 & 0.008 & 0.144 \\
\hline & Sent*Index*EU & & & -0.007 & 0.139 \\
\hline \multirow{3}{*}{ Long-term vs. Short-term Orientation ( $L T O)$} & Sent & 0.773 & 0.136 & 1.095 & $0.054^{*}$ \\
\hline & Sent*Index & 0.001 & 0.966 & 0.001 & 0.839 \\
\hline & Sent*Index*EU & & & -0.011 & $0.008 * * *$ \\
\hline \multirow{3}{*}{ Indulgence vs. Restraint (IVR) } & Sent & 1.073 & $0.015^{* *}$ & 0.666 & 0.196 \\
\hline & Sent*Index & -0.007 & 0.396 & 0.019 & 0.198 \\
\hline & Sent*Index*EU & & & -0.022 & $0.003 * * *$ \\
\hline
\end{tabular}

Model 1: $R_{i, t}=\alpha_{i}+\beta_{i}$ Sent $_{i, t}+\gamma_{i}$ Sent $_{i, t} *$ Index $_{i}+\delta_{i} \psi_{i, t}+\varepsilon_{i, t}$

Model 2: $R_{i, t}=\alpha_{i}+\beta_{i}$ Sent $_{i, t}+\gamma_{i}$ Sent $_{i, t} *$ Index $_{i}+\delta_{i}$ Sent $_{i, t} *$ Index $_{i} * E U+\theta_{i} \psi_{i, t}+\varepsilon_{i, t}$

$*, * *, * * *$ : indicate $0.1,0.05$, and 0.01 significance level, respectively. 
Regarding cultural dimensions, the regression results suggest that the sentiment-return relationship is less affected by national culture than financial development or institutional conditions. The estimated coefficients of the interaction variables between sentiment and the six cultural dimensions are small, ranging from -0.018 ( $\mathrm{p}$-value $=0.001$ ) for $I D V$ to 0.022 (p-value $=0.000$ ) for PDI. Additionally, unlike the development and governance factors, the moderating effect of cultural factors is disparate. The moderating effect is disparate because IDV and IVR decrease, whereas PDI, MAS, UAI, and $L T O$ increase the sentiment impact on market returns. However, only the PDI, IDV, and MAS impacts are statistically significant. Concerning the IDV dimension, we support the papers of Schmeling (2009) [15] and Zaremba et al. (2020) [19], which confirm that collectivistic countries show a more significant sentiment effect on returns than individualistic countries. In a collectivistic country, the investors follow each other and commonly share opinions [19], which leads to stronger herding behavior. As a result, collectivistic societies tend to suffer more from herd-like overreaction, which is a behavioral justification for the sentiment-return nexus, according to Schmeling (2009) [15]. Similarly, in an international study about the cultural impact on investors' herding behavior, Chang and Lin (2015) [41] state that investors active in a more masculine or a higher power-distance culture tend to be more prone to herd-like behavior. Their results signal a stronger sentiment effect on stock markets in masculine and high power-distance societies that agrees with our results for $M A S$ and $P D I$ dimensions.

Lastly, based on the large dispersions in the sentiment effect among European markets, we doubt that national elements might impact this region more powerfully than in Asia. Therefore, a dummy variable for European markets is created. The results we achieve from Model 2 support our speculation because all significant coefficients of the interaction term between sentiment, country-specific factors, and this dummy variable are negative. Nevertheless, the interpretation of MAS and LTO are contradictory to the development and governance factors. Based on the outcomes of Model 1, MAS and LTO are positively associated with the sentiment effect, though the role of LTO is insignificant statistically. Consequently, the negative coefficients of the MAS and LTO's interaction variable claim that Europe is less sensitive than Asia in terms of these cultural impacts. Since Asia is more prone to collective-oriented societies, as discussed in the preceding sections, it is reasonable that Asian investors generally suffer from cognitive biases more than Western investors.

\section{4- Conclusion}

This study examines and reports the sentiment impact on contemporaneous returns in Asian and European stock markets from 2004 to 2016. More crucially, our paper produces the first comprehensive assessment of the role of countryspecific factors on driving the sentiment-return variations. By utilizing fourteen national components representing the degree of financial development, the quality of governance, and the features of culture, we demonstrate that the financial environment and institutional quality are negatively associated with the sentiment effect. Our empirical results suggest that a better financial and governance system mitigates the sentiment effect on market returns and vice versa. The driving role of cultural dimensions, on the contrary, is relatively weak and heterogeneous. PDI, MAS, UAI, and LTO escalate the sentiment effect on stock returns, whereas $I D V$ and $I V R$ diminish the sentiment-return nexus. These conclusions about the role of local characteristics on the sentiment-return relationship can explain the differences in the sentiment effect between individual markets in the same region or between developed and emerging markets, as outlined in our analyses. Moreover, these conclusions are consistent with our regional results because Asia, characterized by less developed markets, collectivistic, masculine, and high power distance societies, suffers more from the sentiment effect compared with Europe. Finally, to the best of our knowledge, we are the first to claim that these country-specific factors play a more important role in European stock markets than Asian ones, excluding cultural dimensions.

In general, we provide not only the latest and thorough statistical evidence but also new insights into the existing literature on the moderating role of local characteristics on sentiment research. An unresolved issue in this study is whether country-level factors influence the return predictability of investor sentiment, which should be investigated further in future work.

\section{5- Declarations}

\section{5-1-Author Contributions}

Conceptualization, N.B.V.; methodology, N.B.V. and Y.S.; writing-original draft preparation, N.B.V. and A.T.T.; writing - review and editing, N.B.V., Y.S. and A.T.T. All authors have read and agreed to the published version of the manuscript.

\section{5-2-Data Availability Statement}

The data presented in this study are available on request from the corresponding author.

\section{5-3- Funding}

The authors received no financial support for the research, authorship, and/or publication of this article. 


\section{5-4- Conflicts of Interest}

The authors declare that there is no conflict of interests regarding the publication of this manuscript. In addition, the ethical issues, including plagiarism, informed consent, misconduct, data fabrication and/or falsification, double publication and/or submission, and redundancies have been completely observed by the authors.

\section{6- References}

[1] Fisher, Kenneth L., and Meir Statman. “Consumer Confidence and Stock Returns.” Journal of Portfolio Management 30, no. 1 (2003): 115-127. doi:10.3905/jpm.2003.319925.

[2] Bathia, Deven, and Don Bredin. “An Examination of Investor Sentiment Effect on G7 Stock Market Returns.” European Journal of Finance 19, no. 9 (2013): 909-37. doi:10.1080/1351847X.2011.636834.

[3] Huang, Dashan, Fuwei Jiang, Jun Tu, and Guofu Zhou. "Investor Sentiment Aligned: A Powerful Predictor of Stock Returns." Review of Financial Studies 28, no. 3 (2015): 791-837. doi:10.1093/rfs/hhu080.

[4] Cheema, Muhammad A., Yimei Man, and Kenneth R. Szulczyk. "Does Investor Sentiment Predict the Near-Term Returns of the Chinese Stock Market?” International Review of Finance 20, no. 1 (2020): 225-33. doi:10.1111/irfi.12202.

[5] Gao, Zhenyu, Haohan Ren, and Bohui Zhang. "Googling Investor Sentiment around the World." Journal of Financial and Quantitative Analysis 55, no. 2 (2020): 549-80. doi:10.1017/S0022109019000061.

[6] Truong, Quang Thai, Quynh Nhu Tran, Walid Bakry, Duc Nguyen, and Somar Al-Mohamad. "Football Sentiment and Stock Market Returns: Evidence from a Frontier Market.” Journal of Behavioral and Experimental Finance 30 (2021): 100472. doi:10.1016/j.jbef.2021.100472.

[7] Lee, Charles M.C., Andrei Shleifer, and Richard H. Thaler. "Investor Sentiment and the Closed - End Fund Puzzle." The Journal of Finance 46, no. 1 (1991): 75-109. doi:10.1111/j.1540-6261.1991.tb03746.x.

[8] Berger, Dave, and H. J. Turtle. “Cross-Sectional Performance and Investor Sentiment in a Multiple Risk Factor Model.” Journal of Banking and Finance 36, no. 4 (2012): 1107-21. doi:10.1016/j.jbankfin.2011.11.001.

[9] Ding, Wenjie, Khelifa Mazouz, and Qingwei Wang. "Investor Sentiment and the Cross-Section of Stock Returns: New Theory and Evidence.” Review of Quantitative Finance and Accounting 53, no. 2 (2019): 493-525. doi:10.1007/s11156-018-0756-Z.

[10] Porta, Rafael La, Florencio Lopez-de-Silanes, Andrei Shleifer, and Robert W. Vishny. "Law and Finance.” Journal of Political Economy 106, no. 6 (1998): 1113-55. doi:10.1086/250042.

[11] Chiou, Wan Jiun Paul, Alice C. Lee, and Cheng Few Lee. "Stock Return, Risk, and Legal Environment around the World." International Review of Economics and Finance 19, no. 1 (2010): 95-105. doi:10.1016/j.iref.2009.05.001.

[12] Turco, Alessia Lo, Daniela Maggioni, and Alberto Zazzaro. "Financial Dependence and Growth: The Role of Input-Output Linkages.” Journal of Economic Behavior and Organization 162 (2019): 308-28. doi:10.1016/j.jebo.2018.11.024.

[13] Chui, Andy C.W., Sheridan Titman, and K. C.John Wei. “Individualism and Momentum around the World.” Journal of Finance 65, no. 1 (2010): 361-92. doi:10.1111/j.1540-6261.2009.01532.x.

[14] Lee, Suin, Christos Pantzalis, and Jung Chul Park. "Does Local Culture Trigger Speculative Investment Behavior?” Journal of Business Research 103 (2019): 71-88. doi:10.1016/j.jbusres.2019.06.011.

[15] Schmeling, Maik. "Investor Sentiment and Stock Returns: Some International Evidence.” Journal of Empirical Finance 16, no. 3 (2009): 394-408. doi:10.1016/j.jempfin.2009.01.002.

[16] Chang, Candie, Robert W. Faff, and Chuan-Yang Hwang. "Local and Global Sentiment Effects, and the Role of Legal, Information and Trading Environments.” SSRN Electronic Journal, 2012. doi:10.2139/ssrn.1800550.

[17] Corredor, Pilar, Elena Ferrer, and Rafael Santamaria. "Investor Sentiment Effect in Stock Markets: Stock Characteristics or Country-Specific Factors?” International Review of Economics and Finance 27 (2013): 572-91. doi:10.1016/j.iref.2013.02.001.

[18] Lee, Chien Chiang, and Mei Ping Chen. "Happiness Sentiments and the Prediction of Cross-Border Country Exchange-Traded Fund Returns.” North American Journal of Economics and Finance 54 (2020): 101254. doi:10.1016/j.najef.2020.101254.

[19] Zaremba, Adam, Adam Szyszka, Huaigang Long, and Dariusz Zawadka. "Business Sentiment and the Cross-Section of Global Equity Returns.” Pacific Basin Finance Journal 61 (2020): 101329. doi:10.1016/j.pacfin.2020.101329.

[20] Corredor, P., E. Ferrer, and R. Santamaria. “The Impact of Investor Sentiment on Stock Returns in Emerging Markets: The Case of Central European Markets.” Eastern European Economics 53, no. 4 (2015): 328-55. doi:10.1080/00128775.2015.1079139.

[21] Lemmon, Michael, and Evgenia Portniaguina. “Consumer Confidence and Asset Prices: Some Empirical Evidence.” Review of Financial Studies 19, no. 4 (2006): 1499-1529. doi:10.1093/rfs/hhj038. 
[22] Bekaert, Geert, and Marie Hoerova. “The VIX, the Variance Premium and Stock Market Volatility.” Journal of Econometrics 183, no. 2 (2014): 181-92. doi:10.1016/j.jeconom.2014.05.008.

[23] Smales, L. A. “The Importance of Fear: Investor Sentiment and Stock Market Returns.” Applied Economics 49, no. 34 (2017): 3395-3421. doi:10.1080/00036846.2016.1259754.

[24] Qadan, Mahmoud, Doron Kliger, and Nir Chen. "Idiosyncratic Volatility, the VIX and Stock Returns." North American Journal of Economics and Finance 47 (2019): 431-41. doi:10.1016/j.najef.2018.06.003.

[25] Kim, Jae H. “Stock Returns and Investors' Mood: Good Day Sunshine or Spurious Correlation?" International Review of Financial Analysis 52 (2017): 94-103. doi:10.1016/j.irfa.2017.05.004.

[26] Khan, Mehwish Aziz, and Eatzaz Ahmad. "Measurement of Investor Sentiment and Its Bi-Directional Contemporaneous and Lead-Lag Relationship with Returns: Evidence from Pakistan.” Sustainability (Switzerland) 11, no. 1 (2018): 1-20. doi:10.3390/su11010094.

[27] Chi, Lixu, Xintian Zhuang, and Dalei Song. "Investor Sentiment in the Chinese Stock Market: An Empirical Analysis." Applied Economics Letters 19, no. 4 (2012): 345-48. doi:10.1080/13504851.2011.577003.

[28] Massa, Massimo, and Vijay Yadav. "Investor Sentiment and Mutual Fund Strategies.” Journal of Financial and Quantitative Analysis 50, no. 4 (2015): 699-727. doi:10.1017/S0022109015000253.

[29] Doukas, John A., and Nikolaos T. Milonas. "Investor Sentiment and the Closed-End Fund Puzzle: Out-of-Sample Evidence." European Financial Management 10, no. 2 (2004): 235-66. doi:10.1111/j.1354-7798.2004.00249.x.

[30] Bathia, Deven, and Don Bredin. “Investor Sentiment: Does It Augment the Performance of Asset Pricing Models?” International Review of Financial Analysis 59 (2018): 290-303. doi:10.1016/j.irfa.2018.03.014.

[31] Chen, Gong meng, Michael Firth, and Oliver M. Rui. "The Dynamic Relation between Stocks Returns, Trading Volume, and Volatility.” Financial Review 36, no. 3 (2001): 153-74. doi:10.1111/j.1540-6288.2001.tb00024.x.

[32] Baker, Malcolm, and Jeremy C. Stein. “Market Liquidity as a Sentiment Indicator.” Journal of Financial Markets 7, no. 3 (2004): 271-99. doi:10.1016/j.finmar.2003.11.005.

[33] Brüggemann, Ralf, Markus Glaser, Steffen Schaarschmidt, and Sandra Stankiewicz. "The Stock Return - Trading Volume Relationship in European Countries: Evidence from Asymmetric Impulse Responses.” Working Paper Series 24 (2014).

[34] Anusakumar, Shangkari V., Ruhani Ali, and Hooy Chee Wooi. "The Effect of Investor Sentiment on Stock Returns: Insight from Emerging Asian Markets.” Asian Academy of Management Journal of Accounting and Finance 13, no. 1 (2017): 159-78. doi:10.21315/aamjaf2017.13.1.7.

[35] Li, Haiqi, Yu Guo, and Sung Y. Park. "Asymmetric Relationship between Investors' Sentiment and Stock Returns: Evidence from a Quantile Non-Causality Test.” International Review of Finance 17, no. 4 (2017): 617-26. doi:10.1111/irfi.12120.

[36] Mujtaba Mian, G., and Srinivasan Sankaraguruswamy. "Investor Sentiment and Stock Market Response to Earnings News." Accounting Review 87, no. 4 (2012): 1357-84. doi:10.2308/accr-50158.

[37] Finter, Philipp, Alexandra Niessen-Ruenzi, and Stefan Ruenzi. "The Impact of Investor Sentiment on the German Stock Market." Zeitschrift Für Betriebswirtschaft 82, no. 2 (2012): 133-63. doi:10.1007/s11573-011-0536-x.

[38] Baker, Malcolm, Jeffrey Wurgler, and Yu Yuan. "Global, Local, and Contagious Investor Sentiment.” Journal of Financial Economics 104, no. 2 (2012): 272-87. doi:10.1016/j.jfineco.2011.11.002.

[39] Zhu, Yanjian, and Xiaoneng Zhu. "European Business Cycles and Stock Return Predictability.” Finance Research Letters 11, no. 4 (2014): 446-53. doi:10.1016/j.frl.2014.10.002.

[40] Prabheesh, K. P., and C. T. Vidya. "Do Business Cycles, Investment-Specific Technology Shocks Matter for Stock Returns?" Economic Modelling 70 (2018): 511-24. doi:10.1016/j.econmod.2017.09.014.

[41] Chang, Chih Hsiang, and Shih Jia Lin. "The Effects of National Culture and Behavioral Pitfalls on Investors' Decision-Making: Herding Behavior in International Stock Markets.” International Review of Economics and Finance 37 (2015): 380-92. doi:10.1016/j.iref.2014.12.010. 